\title{
Effect of fiber surface treatment on the incorporation of carbon nanotubes and on the micromechanical properties of a single-carbon fiber-epoxy matrix composite
}

\author{
M. F. Muñoz-Vélez, A. Valadez-González, P. J. Herrera-Franco* \\ Centro de Investigación Científica de Yucatán, Unidad de materiales, Calle 42 \# 130, 32, Col. Chuburná de Hidalgo, C.P. \\ 97205 Mérida, Yucatán, México,
}

Received 17 January 2017; accepted in revised form 5 April 2017

\begin{abstract}
Multiwall carbon nanotubes (MWCNTs) previously treated with a cationic polymer were incorporated on the surface of carbon fibers modified by three different chemical treatments, namely, oxidation, oxidation-silanization and oxidation-pre-impregnation. Prior to the incorporation of the MWCNTs, the physical surface properties of the fibers were studied by contact angle and the chemical surface properties by X-ray photoelectron spectroscopy (XPS). The interfacial shear strength (IFSS) of the different systems carbon fiber-MWCNTs-matrix was evaluated using the single-fiber fragmentation test (SFFT) and it was observed that the IFSS of the oxidized-pre-impregnated fibers, was considerably higher than that observed for the other fiber-matrix systems. This was attributed to enhanced interfacial interactions because the fiber surface treatments improved the wettability of the carbon fiber and the MWCNTs, which resulted in a better fiber-matrix mechanical interlocking and to the formation of covalent bonds between the different phases of the composite.
\end{abstract}

Keywords: adhesion, reinforcements, multiscale composites, carbon nanotubes, carbon fiber/epoxy matrix composites

\section{Introduction}

It is known that effective mechanical properties of a composite depend on the properties of each of the constituents, and most importantly, on the quality of the fiber-matrix interfacial region, which is based on the interactions between the molecular structures present in the interphase [1-3]. However, in some cases, their application has been limited because of limited fiber-matrix adhesion, as reported in several technical papers, thus encouraging to improve its performance for more demanding technological applications [3-6]. In a fiber-reinforced composite, the applied load is transferred from the matrix to the fiber through shear stresses and if the IFSS is low, lower loads can be transferred to the fiber, thus resulting in a low efficiency composite material $[6,7]$. This problem has motivated many researchers to develop different surface treatments of the carbon fiber aimed at improving the IFSS, such as oxidation treatments that allow the formation of functional groups and removes a weak fiber-surface layer and increase the fiber surface roughness and surface area [8-10]; the non-oxidative treatments use coupling agents such as silane that possess organic functional groups that are capable of reacting with the chemical structure of the polymer [11]; the fiber surface treatment referred to as pre-impregnation or sizing results in a thin polymeric layer on the carbon fiber surface. All these will result in the formation of an interfacial region with properties differing from those of the fiber or the matrix. With that application of an epoxy sizing, it is possible to obtain an interphase with a high elastic modulus and low fracture toughness, because of differences in their stoichiometry; this should result in

$\overline{{ }^{*} \text { Corresponding author, e-mail: pherrera@cicy.mx }}$

(C) BME-PT 
an increment of the stress transfer to the fiber, and preventing an interfacial crack growth. Additionally, with these fiber-surface treatments it is possible to change surface energy, thus improving the fiber wettability with the polymeric resin [7,9]. The subject of engineering the fiber/matrix interphases with nanofillers have been widely investigated and several reports are available in the open scientific literature [12-17]. The incorporation of CNTs on the carbon fiber surface has been one of the alternatives to improve the IFSS. This is attributed to their exceptional properties such as: high elastic modulus and tensile strength, flexibility, low density and a negligible coefficient of thermal expansion [18-20]. Additionally, they possess a high surface area, that should result in an improved stress transfer [21]. However, in order to take advantage of the CNTs outstanding properties, it is necessary to simultaneously optimize four structural parameters: 1) the fiber aspect ratio of the CNTs; 2) their dispersion; 3) the homogenous distribution of the CNTs in the matrix and 4) the interfacial adhesion CNT-polymer [22]. In the search to optimize these parameters, several methods of CNTs deposition on the carbon surface have been reported. Among them are: the direct synthesis of the CNTs on the carbon fiber surface by the technique of carbon vapor deposition (CVD). This method allows a good control of their dispersion, distribution, orientation and fiber aspect ratio of the CNTs, but it may result in a structural damage to the carbon fibers because of the high temperature required in this process. Additionally, the application at an industrial scale has been severely questioned because of the limitations imposed by the dimensions of the furnace [21-23]. Electrophoresis is another technique reported in the technical literature and is based on the capacity of the CNTs to respond to an electric field, which allows a uniform deposition of the CNT on the fiber surface upon application of an electric potential, which allows the previously oxidized CNTs charged negatively to migrate towards the carbon fiber which is charged positively. However, similarly to the CVD, electrophoresis possess limitations for a large scale production [23, 24]. In this study, the effect of the carbon fiber surface treatments on the incorporation of the CNTs and on the micromechanical properties of single-filament carbon fiber-CNTs-epoxy resin (CF-CNTs-ER) was studied. The carbon fiber surface treatments used were: fiber surface oxidation, silanization and pre-impregnation or sizing. The physico-chemical characteristics originated with these treatments and their influence on the CNTs deposition and their role in the chemical interactions between fiber-CNTs were evaluated using XPS. The contact angle was also estimated to determine the changes in the carbon fiber wettability with the epoxy resin. The effect produced by the presence of the CNTs in the interface of each of the different CF-CNTs-ER systems was studied using the single-fiber fragmentation test to estimate the IFSS together with an analysis of birefringence patterns observed for each of the systems.

\section{Materials and methods}

\subsection{Materials}

Intermediate modulus carbon fibers, IM7 with a density of $1.78 \mathrm{~g} / \mathrm{cm}^{3}$ and a $5.2 \mu \mathrm{m}$ average diameter were used, Hexcel Dublin, USA [25]. Multiwall carbon nanotubes (MWCNTs) from Mknano Co, New York, USA; whose diameters are between $8-15 \mathrm{~nm}$ and lengths between 0.5 to $2 \mu \mathrm{m}$ and a purity grade of $95 \%$ were used. As a matrix, epoxy resin (DER 331) based on diglycidyl ether of bisphenol A (DGEBA) from Dow Chemical Inc, Ciudad de Mexico, Mexico; was used together with ethylene diamine ( $99 \%$ purity) from Sigma-Aldrich Co., Mexico, as a curing agent. Besides the chemical surface treatments performed on the CNTs and the carbon fiber, (3-glycidyloxypropyl)-trimethoxysilane (Z-6040) and polyethyleneimine in solution (PEI) both from SigmaAldrich Co., Mexico, were used as coupling agents.

\subsection{Treatment with of the MWCNTs cationic polymers}

First, the MWCNTs were oxidized by immersing them in an acid solution to promote the formation of functional groups (carbonyl and hydroxyl) on their surface. $0.3 \mathrm{~g}$ of MWCNTs were mixed with $100 \mathrm{~mL}$ of an aqueous solution $(8 \mathrm{M})$ of nitric acid $\left(\mathrm{HNO}_{3}\right)$, with continuous mechanical stirring for $15 \mathrm{~min}$ at $60^{\circ} \mathrm{C}$. This process was repeated using an aqueous solution of hydrogen peroxide $\left(\mathrm{H}_{2} \mathrm{O}_{2}\right) 30 \% \mathrm{w} / \mathrm{w}$. and then the MWCNTs were dried in an oven during 24 hours at $100^{\circ} \mathrm{C}$. After oxidation of the MWCNTs, they were treated with a cationic polymer using the same process reported by Kamae et al. [23], by continuous stirring in a solution of polyethylenimine (PEI), sodium chloride $(\mathrm{NaCl})$ and distilled water (the volume of the solution was $250 \mathrm{~mL}$ ), during $10 \mathrm{~min}$; the proportion of MWCNTs, PEI and $\mathrm{NaCl}$ 
in the solution was of $0.070,0.014$ and $0.10 \mathrm{wt} \%$, respectively. This solution was continuously agitated using an ultrasonic probe $(100 \mathrm{~W})$ for 2 hours, and then, the excess of PEI and $\mathrm{NaCl}$ were eliminated by filtering with a $0.25 \mu \mathrm{m}$ pore size filter. The MWCNTs were subjected to the ultrasonic process of dispersion in distilled water at $20 \mathrm{~W}$ during 15 minutes (this process was performed twice). Finally, the filtered MWCNTs treated with PEI were dispersed in water, using the ultrasonic probe in order to obtain a suspension of MWCNTs/water [23].

\subsection{Surface modification of the carbon fibers and MWCNTs deposition}

The nomenclature used for the carbon fiber surface treatments is the following: (1) WOS, refers to the unsized fiber after commercial sizing removal; (2) Ox, refers to the unsized fiber oxidized with $\mathrm{HNO}_{3}$; (3) $\mathrm{Ox}+\mathrm{Si}$, refers to the fiber previously referred to as 'Ox' treated with a silane coupling agent, and (4) Ox + PRE refers to the 'Ox' treatment plus an epoxy resin sizing. To eliminate the commercial sizing of the carbon fibers, they were refluxed in methyl ethyl ketone for $96 \mathrm{~h}$ at $80^{\circ} \mathrm{C}$ using a Soxhlet extractor. Next, the fibers were washed with acetone and dried in an oven at $100^{\circ} \mathrm{C}$ for $2 \mathrm{~h}$. The carbon fibers were oxidized (Ox fibers) by immersing them in $\mathrm{HNO}_{3}\left(70 \%\right.$ purity), at $100^{\circ} \mathrm{C}$, during 6 hours, in a Pyrex glass reaction kettle. Finally, the fibers were washed with acetone to remove acid residues and dried in an oven at $100^{\circ} \mathrm{C}$ for 24 hours. The silanization treatment $(\mathrm{Ox}+\mathrm{Si}$ fiber) was carried out in a $50 \% \mathrm{v} / \mathrm{v}$ water-methanol solution, to which $5 \% \mathrm{w} / \mathrm{w}$ silane (with respect to the fiber) was added. The volume of the solution was adjusted to a ratio of $0.01 \% \mathrm{w} / \mathrm{w}$ the silane. For the hydrolysis of the silane, the $\mathrm{pH}$ of the solution was adjusted to approximately 4 and then stirred for 1 hour. The fibers were immersed in the solution and subjected to an ultrasonic bath for 2 hours. Finally the fibers were dried at $120^{\circ} \mathrm{C}$ for 2 hours. The Ox + PRE treatment was performed by coating the Ox fiber with an epoxysilane solution by immersing them for 20 minutes in a solution of epoxy resin DER 331/tetrahydrofuran (THF) $(1 \mathrm{~g} / 80 \mathrm{~mL})$, where the silane coupling agent had been previously added at $5 \% \mathrm{v} / \mathrm{v}$ with respect to the epoxy resin. Once the fiber was pre-impregnated, the moisture and the solvent were removed, using vacuum for 24 hours.
The carbon fibers treated with the different methods described above were immersed in a suspension of MWCNTs/water for 1 hour with ultrasonication $(20 \mathrm{~W})$. Finally the $\mathrm{Ox}$ and $\mathrm{Ox}+\mathrm{Si}$ fibers were dried at $80^{\circ} \mathrm{C}$ for 2 hours and then at $120^{\circ} \mathrm{C}$ for 2 hours while the Ox + PRE fibers were vacuum-dried at room temperature for 24 hours.

\subsection{Physico-chemical evaluation of the modified carbon fiber surface}

The physico-chemical analysis of each the modified carbon-fibers surfaces was performed using the XPS technique using a K-Alpha spectrometer of photoelectrons with an X-ray source (Thermo Scientific $^{\mathrm{TM}}$, USA). Areas of $400 \mu \mathrm{m}^{2}$ were analyzed with a $40 \mathrm{~W} \mathrm{Al} \mathrm{K \alpha}$ monochromatic source operating at $12 \mathrm{kV}$. The energy was calibrated with the $\mathrm{C}_{1 \mathrm{~s}}$ at $284.6 \mathrm{eV}$ as a reference. The deconvolution of the peaks and an elemental quantitative composition was determined using the Thermo Scientic ${ }^{\mathrm{TM}}$ Advantage commercial software.

To assess the effect of the fiber-surface chemical treatments on the carbon fiber wettability by the epoxy resin, the contact angle between the carbon fiber and a drop of epoxy resin (Figure 1a) deposited therein was determined (see Figure 1b). The estimation of the contact angle $(\theta)$ was performed using the $L-K$ method proposed by Yamaka et al. [26], which is based on the analysis of the geometry of the drop profile, given by Equation (1), solved using 'The shooting Method', a numerical method used for non-linear problems (Figure 1c), with boundary conditions at point $\mathrm{C}$ (Figure $1 \mathrm{~b}$ ), where $y_{\mathrm{c}}$ is the radius of the fiber and $[\mathrm{d} y / \mathrm{d} x]_{\mathrm{x}=\mathrm{c}}$ is the tangent of the contact angle $(\theta)$. This allowed the construction of a graph $L$ vs $K$ (where $L=l / d$ and $K=k / d$ ) which theoretically relates the length $(l)$ and height $(k)$ of the drop, as a function of the term $\Delta P / \gamma_{\mathrm{LV}}$ (which was assumed to be constant) and the contact angle $(\theta)$, for a fiber with radius equal to 1 (see Equation (1)):

$\frac{\mathrm{d}^{2} y}{\mathrm{~d} x^{2}}=-\frac{\Delta P}{\gamma_{\mathrm{LV}}}\left[1+\left(\frac{\mathrm{d} y}{\mathrm{~d} x}\right)^{2}\right]^{\frac{3}{2}}+\frac{\left[1+\left(\frac{\mathrm{d} y}{\mathrm{~d} x}\right)^{2}\right]}{y}$

where $\Delta P$ is the pressure difference between liquid and solid phases and $\gamma_{\mathrm{LV}}$ is the surface tension between a liquid and a gas. The parameters $l, k$ and carbon fiber diameter $(d)$ were experimentally estimated and compared with those obtained theoretically, 

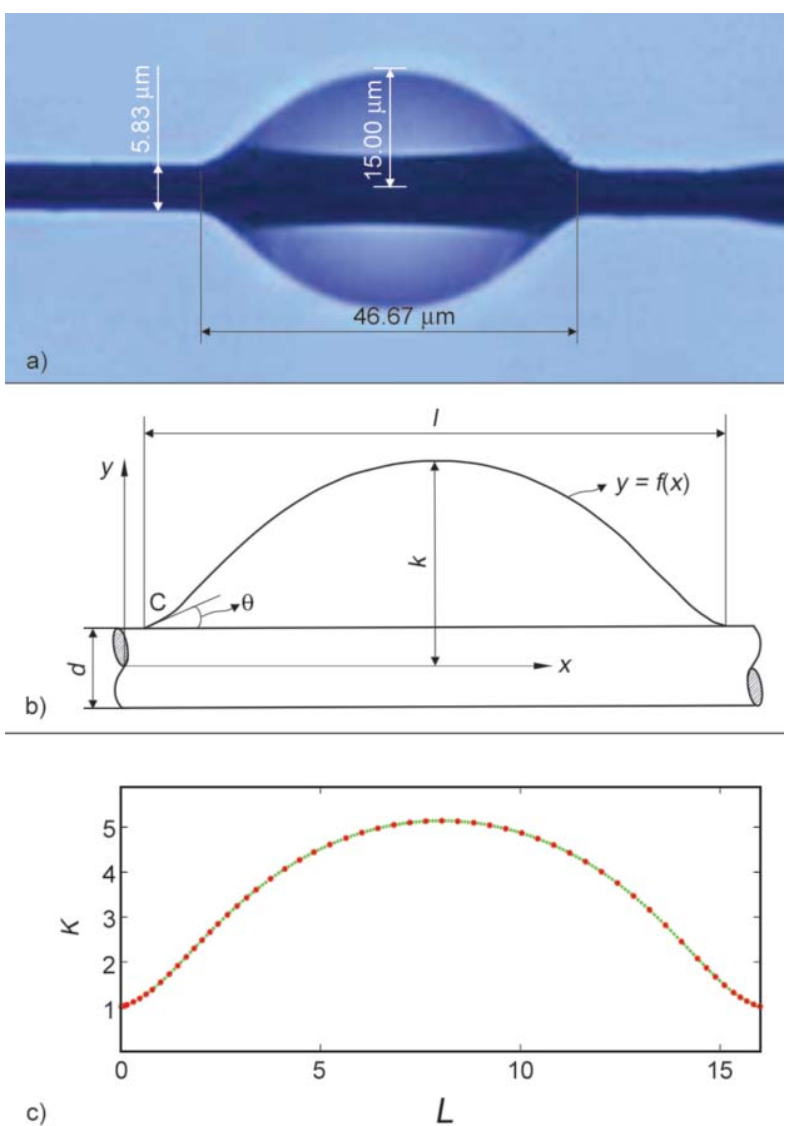

$L$

Figure 1. a) Image taken at $100 \times$ magnification, b) schematic representation and c) Drop profile estimated using Matlab of an epoxy resin drop deposited on the carbon fiber

using the $L$ vs $K$ graph, in order to determine the corresponding contact angle of each of the evaluated drops. The drop parameters were measured using a Leica DM LM optical microscope, equipped with a $100 \times$ objective lens, and an Andor DV401 CCD camera and the Image Pro Plus image analyzer software. Sixty drops of each were analyzed for each surface treatment.

To study the location of the interfacial failure, either at the fiber-matrix interface or at the resin, the same drops used to study the wettability of the modified carbon fiber surfaces, were also loaded up to debonding off the fiber.

The microdrops were prepared depositing a small amount of resin onto the fiber in the form of several microdrops. Long fibers $(15 \mathrm{~cm})$ were stretched across a rectangular frame and held in tension while drops of random sizes were deposited on them with the aid of a very thin hypodermic needle and cured as described in section 2.5. For loading, one end of the fiber specimen was fixed with adhesive to a metal tab which was connected to a $50 \mathrm{~g}$ load-cell mounted on the frame of the MINIMAT. An attachment fitted on the cross-head of the MINIMAT tensile testing machine, equipped with flat, rectangular cross-section blades was used to shear the drop off the fiber at a rate of about $0.02 \mathrm{~mm} / \mathrm{min}$. The location of the failure surface, once the micro drops were sheared off the fiber was observed using SEM.

\subsection{Evaluation of the MWCNTs deposition on the carbon fiber surface and the IFSS}

The morphological differences of the coating of MWCNTs on the carbon fibers were observed for each of the surface chemical treatments using a scanning electron microscope (SEM) (model JSM-6360 from JOEL USA). Additionally, the SFFT was used to determine the IFSS between the epoxy matrix and the carbon monofilaments, where the contribution of the WOS, Ox, Ox + Si and Ox treatment + PRE, and the presence of MWCNTs at the interface of each of these fiber-matrix systems, was evaluated.

Manufacture of the SFFT specimens was performed using silicone molds with 8 cavities for dogbonetype specimens with a total length of $63.50 \mathrm{~mm}$, a width of $3.96 \mathrm{~mm}$, thickness $1.58 \mathrm{~mm}$ and a gage length of $25.4 \mathrm{~mm}$. Epoxy resin DER 331was crosslinked with Ethylene diamine using a stoichiometric ratio of 100:13.8 w/w, and then carefully poured into the mold cavities to avoid disturbing the fibers. The curing process was carried out using the following temperature cycle: $23^{\circ} \mathrm{C}(45 \mathrm{~min}), 50^{\circ} \mathrm{C}(1 \mathrm{~h}), 70^{\circ} \mathrm{C}$ $(1 \mathrm{~h}), 90^{\circ} \mathrm{C}(1 \mathrm{~h}), 120^{\circ} \mathrm{C}(1 \mathrm{~h})$ and $150^{\circ} \mathrm{C}(3 \mathrm{~h})$. Upon loading the samples, tensile forces are transferred to the carbon fiber through the interfacial region. Gradual deformation of the specimen will cause the tensile strength of the fiber to be exceeded at some points, and with continued increase of the load applied, the fiber fracture continuously until the fiber is divided in short fragments and this fragmentation process stops; at this point, the fiber fragments length is referred to as 'the critical length $\left(l_{\mathrm{c}}\right)$ ' [27]. Drzal et al. [28], who studied the statistical distribution of the fragments length and found that it fits well into a two parameters Weibull distribution and the IFSS is given by Equation (2):

$\tau=\frac{\sigma_{\mathrm{f}}}{2 \beta} \Gamma\left(1-\frac{1}{\alpha}\right)$

where $\sigma_{\mathrm{f}}$ is the maximum tensile strength of the fiber extrapolated to the $l_{\mathrm{c}}$ fiber length, $\alpha$ and $\beta$ are the shape and scale parameters of the Weibull distribution 
of $l_{d} d d$, and $\Gamma$ is the gamma function. This test was performed using a MINIMAT test machine, from USA, at a strain rate of $0.02 \mathrm{~mm} / \mathrm{min}$, equipped with a $100 \mathrm{~N}$ load cell, an fitted under and optical microscope with polarized light. The measurement of the fiber fragment lengths was performed using a MRS350 digital camera calibrated using a micrometer scale.

\section{Results and discussion}

\subsection{XPS physico-chemical evaluation of the surface treated carbon fibers}

The elemental chemical composition, obtained by the XPS technique, for the surface treated carbon fibers is shown in Table 1.

It was found that for the different fibers evaluated, carbon $(\mathrm{C})$ and oxygen $(\mathrm{O})$ predominate. Also, in the Ox and Ox-Si fibers, an increase of the presence of oxygen in approximately a $230 \%$ was attributed to the generation of carbonyl, hydroxyl and carboxylic groups from the fiber surface oxidation [9]. In addition, for the Ox-Si and Ox-Pre fibers, 3.80 and 3.62\% silicon $(\mathrm{Si})$ was found, respectively, confirming the presence of the silane on the fiber surface. From the deconvolution of peak $\mathrm{C}_{1 \mathrm{~s}}$ (Figure 2), it was possible to identify five main peaks: the $\mathrm{sp}^{2}$ hybridization or carbon-carbon double bond $(\mathrm{C}=\mathrm{C})$, the carbon-carbon single bond $(\mathrm{C}-\mathrm{C})$, hydroxyl groups $(\mathrm{CO})$, carbonyl groups $(\mathrm{C}=\mathrm{O})$ and carboxylic acids $(\mathrm{COOH})[2,3$, $29,30]$. The binding energy and the atomic percentage (with respect to the amount of carbon in each sample) of each of the peaks are presented in Table 2.

Table 1. Elemental composition of carbon fibers with different treatments

\begin{tabular}{|l|c|c|c|}
\hline $\begin{array}{c}\text { Element } \\
\text { [Atomic \%] }\end{array}$ & C & O & Si \\
\hline Fiber WOS & 88.72 & 7.18 & - \\
\hline Fiber Ox & 73.14 & 23.90 & - \\
\hline Fiber Ox-Si & 70.78 & 23.60 & 3.80 \\
\hline Fiber Ox-PRE & 79.20 & 17.18 & 3.62 \\
\hline
\end{tabular}

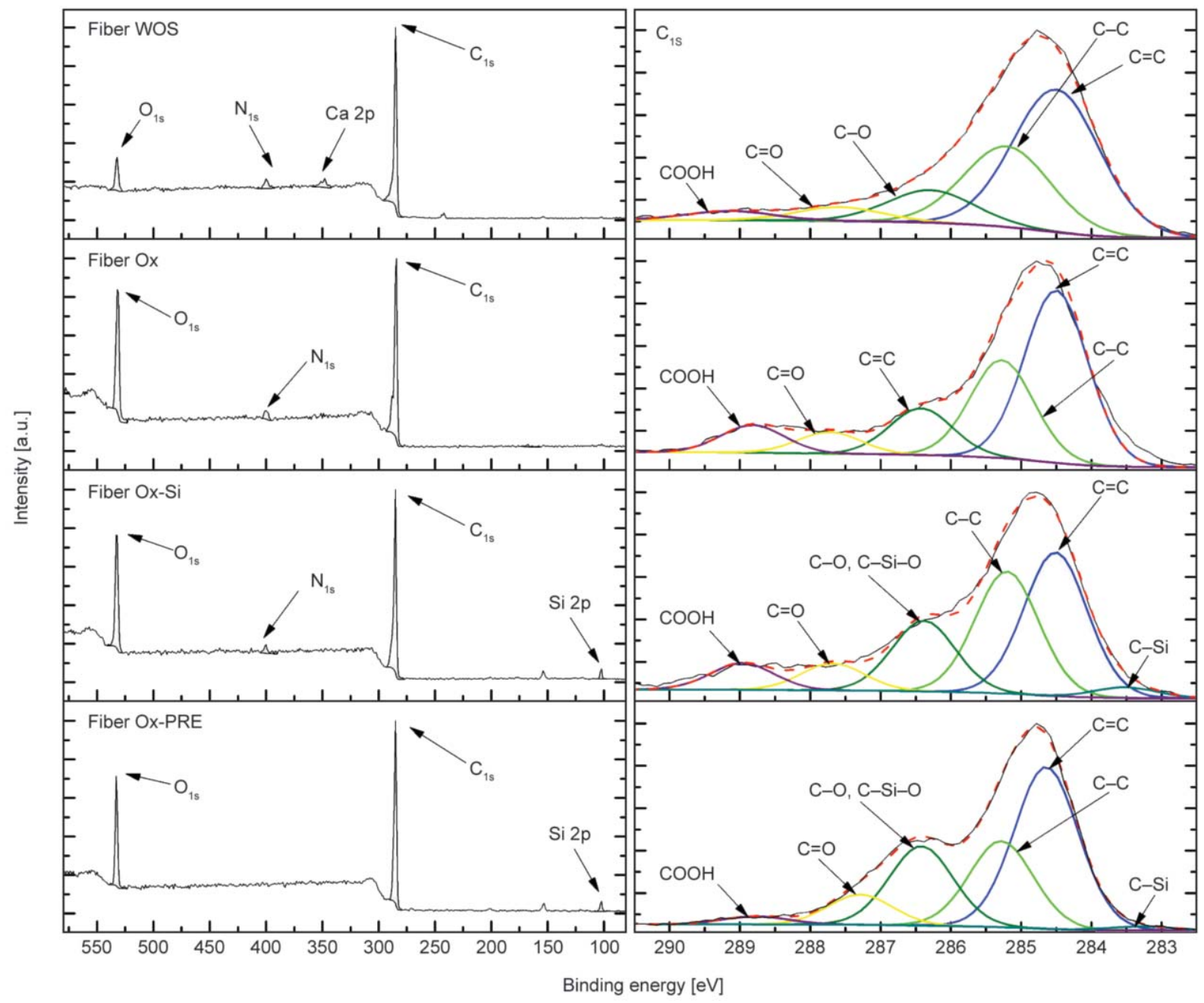

Figure 2. XPS survey spectral and $\mathrm{C}_{1 \mathrm{~s}}$ of high resolution of the carbon fibers with the different chemical surface treatments 
Table 2. Relative percentages of $\mathrm{C}_{1 \mathrm{~s}}$ and the respective chemical bond assignment

\begin{tabular}{|c|c|c|c|c|c|}
\hline \multirow{2}{*}{ Chemical bond } & \multirow{2}{*}{$\begin{array}{c}\text { Peak BE } \\
{[\mathrm{eV}]}\end{array}$} & Fiber WOS & Fiber Ox & Fiber Ox-Si & Fiber Ox-PRE \\
\hline & & \multicolumn{4}{|c|}{ [Atomic \%] } \\
\hline $\mathrm{C}=\mathrm{C}$ & $284.50-284.64$ & 51.16 & 47.08 & 35.83 & 43.85 \\
\hline $\mathrm{C}-\mathrm{C}$ & $285.20-285.28$ & 28.93 & 26.75 & 30.46 & 23.28 \\
\hline $\mathrm{C}-\mathrm{O}, \mathrm{Si}-\mathrm{O}-\mathrm{C}$ & $286.29-286.42$ & 11.67 & 12.76 & 17.66 & 21.45 \\
\hline $\mathrm{C}=\mathrm{O}$ & $287.29-287.73$ & 4.98 & 5.87 & 6.72 & 8.16 \\
\hline $\mathrm{COOH}$ & $288.77-289.13$ & 3.26 & 7.53 & 6.69 & 2.17 \\
\hline $\mathrm{C}-\mathrm{Si}$ & $283.30-283.51$ & - & - & 2.64 & 1.09 \\
\hline
\end{tabular}

The chemical analysis of the $\mathrm{Ox}$ shows an increase in the peaks assigned to $\mathrm{CO}, \mathrm{C}=\mathrm{O}$ and $\mathrm{COOH}$ (Figure 2), corroborating the formation of the aforementioned functional groups on the surface of the fiber, due to the fiber oxidation, and explains the significant increase in oxygen in the sample. Furthermore, from the XPS high-resolution $\mathrm{C}_{1 \mathrm{~s}}$, the spectrum of the Ox-Si fiber, evidenced the appearance of a new peak at around $283.3 \mathrm{eV}$, which has been assigned to the $\mathrm{C}-\mathrm{Si}$ bond [3, 29, 31], corroborating the presence of the silane on the sample. In addition, growth of the $286.6 \mathrm{eV}$ peak is observed, which could be due to the presence of the $\mathrm{Si}-\mathrm{O}-\mathrm{C}$ bond and/or to the epoxide groups of the silane structure $[3,9,32]$.

The formation of the $\mathrm{Si}-\mathrm{O}-\mathrm{C}$ covalent bond appears to be generated from the reaction and subsequent condensation between the silane and the carboxylic acid groups (Figure 3), due to a decrease in the $\mathrm{COOH}$ peak and an increase in the $\mathrm{C}=\mathrm{O}$, with respect to the Ox fiber. Similarly, it is possible to rule out that the increase in this band is related to the presence of hydroxyls $(\mathrm{OH})$ in the hydrolyzed silane, because in the analysis of elemental composition, there was no significant change in the $\mathrm{O} / \mathrm{C}$ ratio $(0.33)$ on the surface of the sample $\mathrm{Ox}-\mathrm{Si}$, with respect to the Ox fiber. The high-resolution $\mathrm{C}_{1 \mathrm{~s}}$ spectra of the Ox-PRE fiber besides the peak assigned to $\mathrm{C}-\mathrm{Si}$ (confirming the presence of silane on the sample surface) an increase of the $\mathrm{CO}$ peak of 68.10 and $21.46 \%$ with the $\mathrm{C}-\mathrm{Si}$

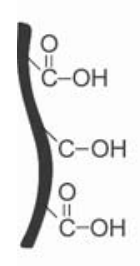

Fiber Ox
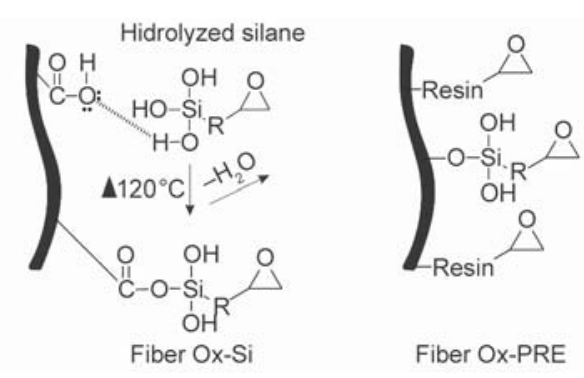

Fiber Ox-PRE
Figure 3. Schematic representation of chemical interactions on different surface treatments peak, respectively, which is attributed to the presence of epoxide groups present in the chemical structure of the resin coating [9, 32]. A significant decrease in the peak assigned to $\mathrm{COOH}$ was observed, which allows saying that the surface chemistry of the OxPRE fiber is dominated by the epoxy coating, hiding the functional groups promoted with the oxidation treatment.

\subsection{Contact angle between the epoxy resin and surface modified fibers without MWCNTs}

The contact angle is shown in Figure 4 and the influence of the different surface treatments on their wettability with the DER 331 resin can be seen. As observed, there is a tendency of the contact angle to decrease in order of magnitude according to the treatments: WOS fiber $>$ Ox fiber $>$ Ox-Si fiber $>$ Ox-PRE fiber. However, according to the dispersion of the data, the contact angle for the WOS and Ox fibers do not show significant differences like for the $\mathrm{Ox}$ and Ox-Si fibers. The decrease in contact angle is significant between the WOS, Ox-Si and Ox-PRE fibers. This decrease is attributed to the increase in the number of polar components such as $\mathrm{CO}, \mathrm{C}=\mathrm{O}$ and $\mathrm{COOH}$, promoted by the oxidation treatment, which

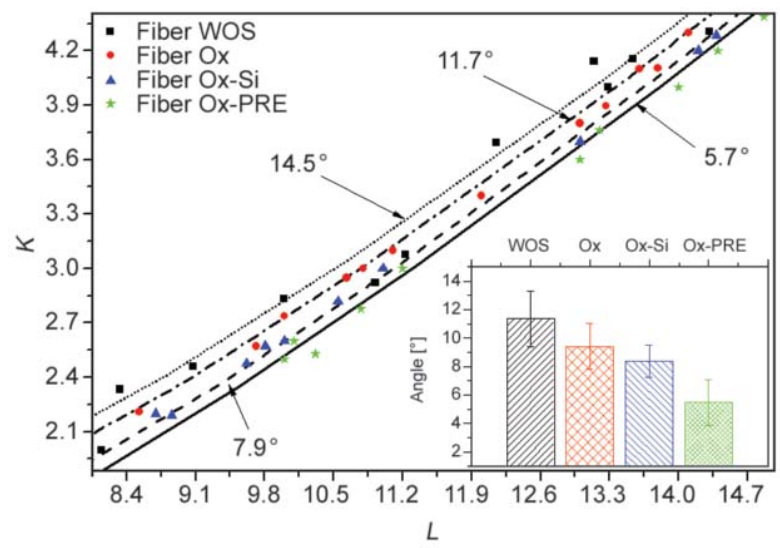

Figure 4. Graph of $L$ vs $K$ according to the Yamaki and Katayama criteria. Insert: Contact angle of surface modified carbon fibers. 
increase the surface energy of the sample allowing a better wettability with the polar epoxy resin $[2,3,33$, 34]. Also, for the Ox-Si fibers epoxide groups are present on their surface, which together with the polar components generated in the oxidation, allow them to have a greater capacity to be wetted by the epoxy resin. The fibers with epoxy coating (Ox-PRE) showed the lowest contact angle, which decreased by $42.03 \%$ with respect to Ox fiber. This is because the epoxy resin DER 331 is compatible and soluble in the epoxy coating of the Ox-PRE fiber, which allows a greater degree of wettability and infiltration of the resin drop on the surface of the fiber [28].

It is evident that the different fiber surface treatments result in a change of the fiber free surface energy as reflected by the change in contact angle. Jiang and Pickering [35] reported that the use of the Yamaki and Katayama criteria to study the structure-property relationships for recycled carbon fibers is able to detect changes of the contact angle resulting from the pyrolysis of the carbon fibers. From both, the contact angle and the concept of work of adhesion they estimated the surface free energy of the fibers.

\subsection{Analysis of the incorporation of MWCNTs on the carbon fiber surface by SEM}

Figure 5 (left column) shows the SEM micrographs of the fibers without MWCNTs. For the WOS sample, the presence of particles on the surface of the fiber can observed, and it may be related to the commercial sizing not removed with the chemical treatment. The micrograph of the sample Ox presents an apparent change in surface roughness; this effect has been attributed to the influence of oxidation treatment on the surface of the fiber, which removes the commercial sizing and also causes surface defects $[4,36]$; The image of the Ox-PRE fiber surface, shows that the sizing covers the carbon fiber homogeneously. In Figure 5 (right column), it is evident that the MWCNTs were deposited on the carbon fiber surfaces in all cases (Ox, Ox-Si and Ox-PRE). For the Ox-CNTs fibers, the coating with MWCNTs shows the generation of a large amount of agglomerations, related to the attraction effect between carbon fibers, (with partial negative charge due to the oxidation, and the presence of $\mathrm{CO}, \mathrm{C}=\mathrm{O}$ and $\mathrm{COOH}$ ) and the MWCNTs with positive partial charge (protonated nitrogen). The deposition of CNTs observed on the surface of the Ox-Si-CNT fiber, has a good distribution of MWCNTs over the whole carbon fiber surface, however, their dispersion is affected, because they have a tendency to form agglomerates, because of the presence of silane, which can chemically interact with the amines on the PEI coating the MWCNTs through the epoxy ring located at its end.

As for the morphology of the coating with CNTs of the Ox-PRE-CNT fibers, a good distribution and a better dispersion than that observed for the Ox-Si fibers was noticed; however, there are some isolated agglomerations, which could be attributed to interaction of the MWCNTs with zones of high presence of the epoxy coating on the fiber surface.

\section{Estimation of the interfacial shear strength (IFSS)}

Figure 6, shows the distribution of the ratio of the saturation fiber length/fiber diameter $\left(l_{\mathrm{s}} / d\right)$ for each of the evaluated systems and it is seen that the magnitude of the mean of the distribution for the non-MWCNTs systems is in the following order: WOS $>\mathrm{Ox}>\mathrm{Ox}-\mathrm{Si}$ $>$ Ox-PRE. It can be said that the surface treatments promoted a better interfacial quality because it is widely known that a low $l_{\mathrm{c}} / d$ ratio is a direct parameter, indicator of good fiber-matrix interfacial quality. Also, the systems with Ox-PRE fiber show the best fiber-matrix interface improvement.

Similarly, for systems with MWCNTs, the mean of the distribution is lower in all cases relative to the reference surface treatment without MWCNTs, revealing that the presence of the MWCNTs at the fibermatrix interface improves the quality of the interfacial properties of the single-fiber composite. It is also noticed when the MWCNTs are deposited on the carbon fibers with previous Ox-PRE treatment this improvement is the largest. The $l_{\mathrm{s}} / d$ distribution in systems with Ox-CNT and Ox-Si-CNT fibers is wider than in systems with Ox and Ox-Si fibers, respectively; which shows the higher variability in the fragment distribution attributed to the non-homogeneity of the MWCNTs deposit on the carbon fiber. Also, Ox-PRE-CNT fibers have a lower dispersion distribution than the systems with Ox-PRE fibers, thus corroborating the good dispersion and distribution of the MWCNTs obtained by the pre-impregnation method with epoxy resin.

The IFSS results and the schematic representation of the possible interfacial interactions for the different fiber surface treatments with and without MWCNTs are shown in Table 3. It can be seen that fiber-matrix systems with Ox fibers have a higher IFSS than the WOS fibers. This increase has been attributed mainly 

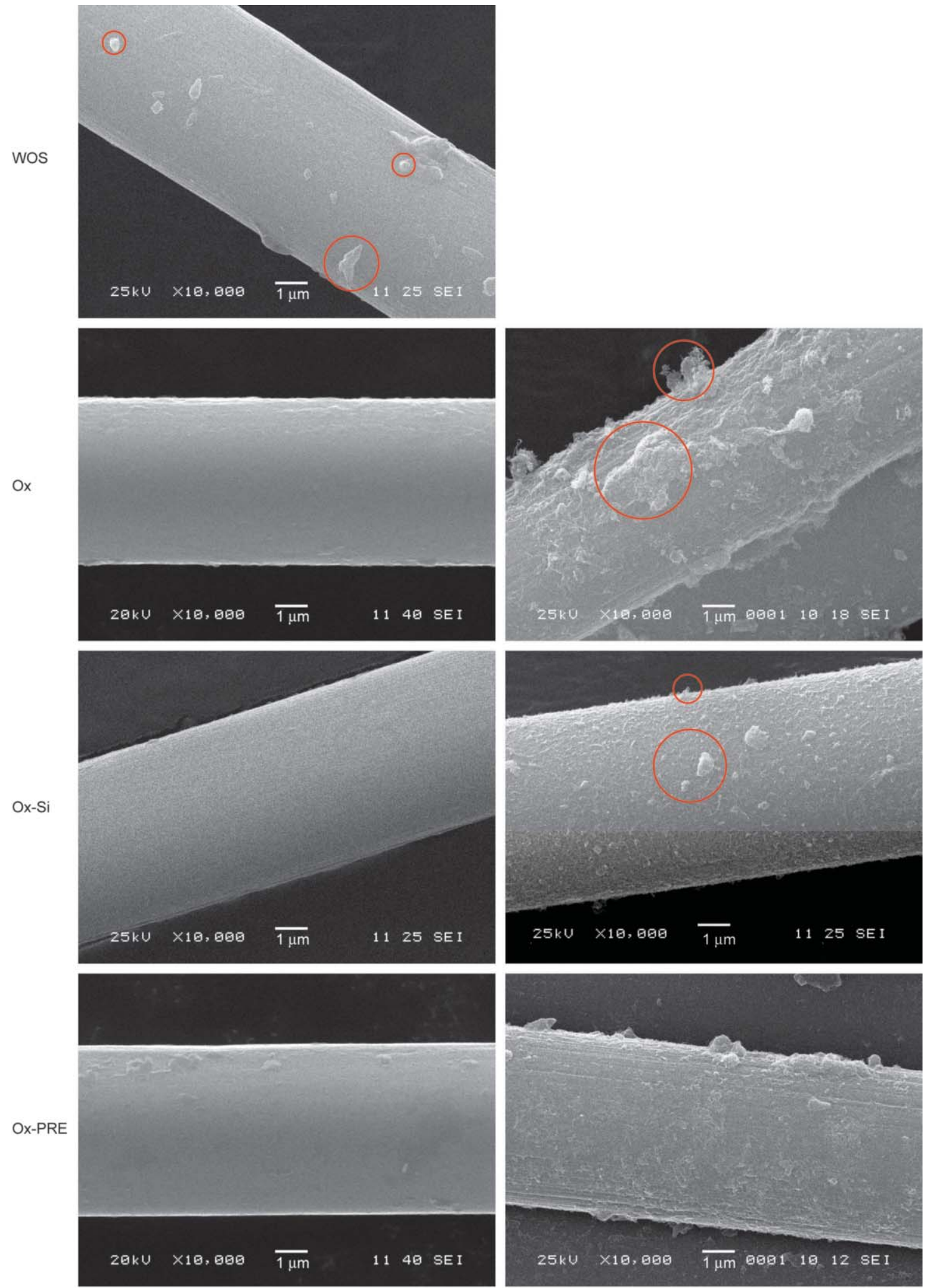

Without MWCNTs

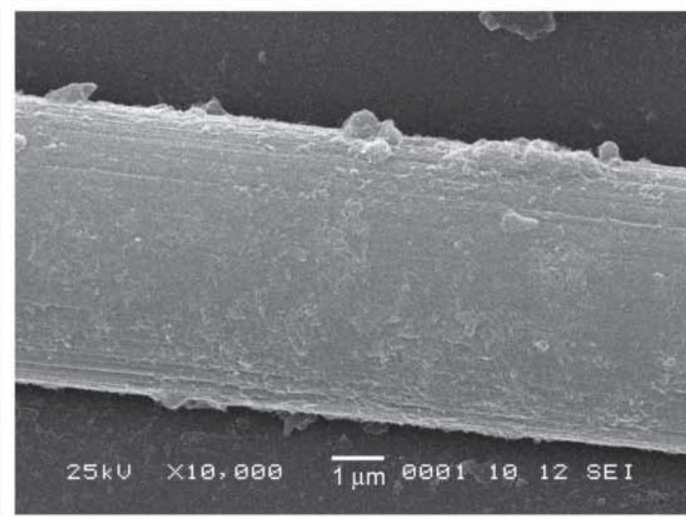

With MWCNTs

Figure 5. SEM micrographs $(10000 \times)$ of carbon fibers without MWCNTs (left) and with MWCNTs (right) on the carbon fiber surface.

to two interfacial adhesion mechanisms: 1) mechanical anchorage, which is promoted by the increase in fiber roughness during oxidation treatment as observed by Fitzer et al. [36] and (2) to fiber-matrix chemical interactions between the functional groups present in the Ox fibers $(\mathrm{C}-\mathrm{OH}, \mathrm{C}=\mathrm{O}$ and $\mathrm{COOH})$ 


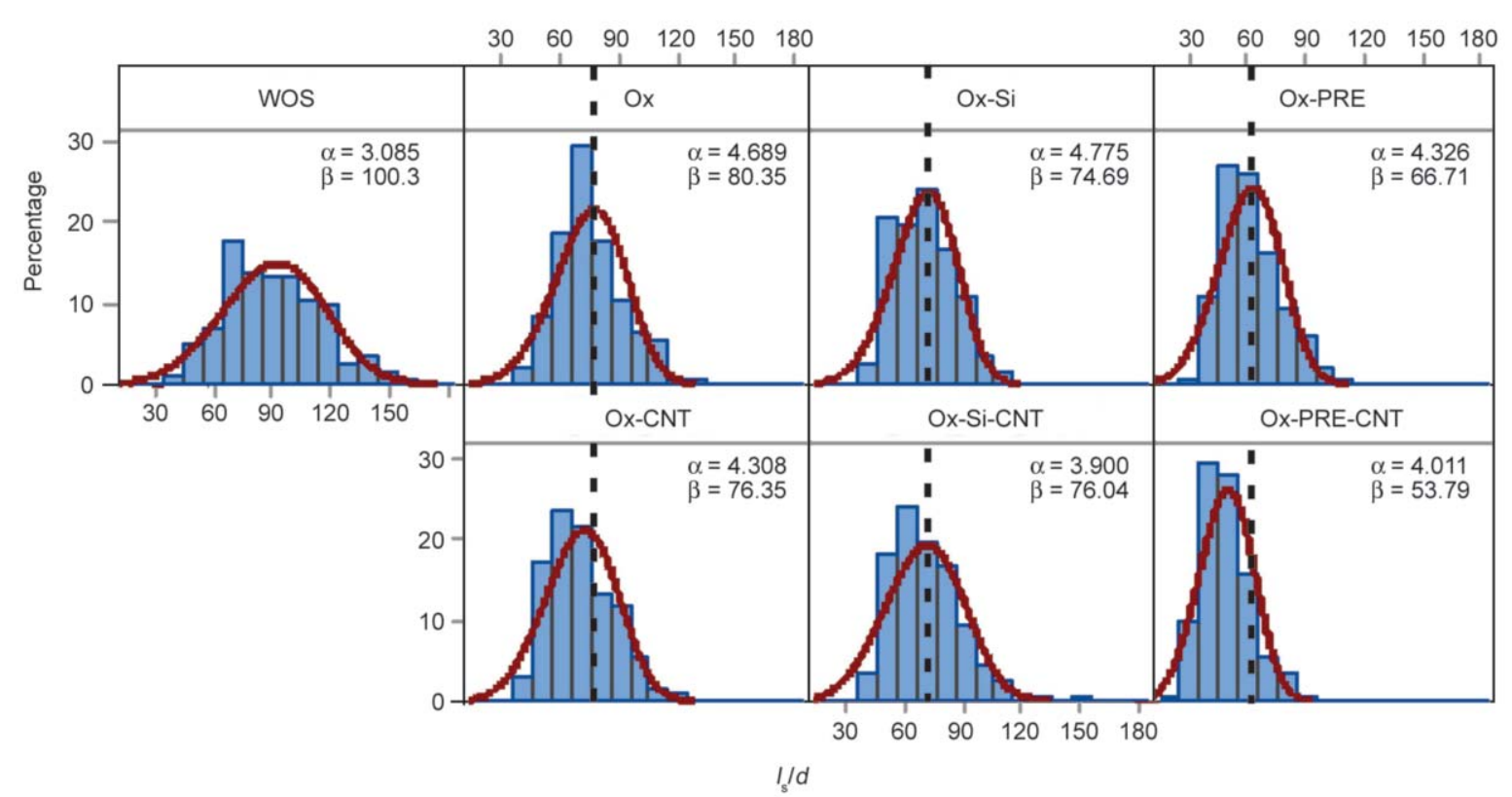

Figure 6. Distribution of the ratio of the saturation fiber length/fiber diameter $\left(l_{\mathrm{s}} / d\right)$ for each of the evaluated fiber-matrix systems

Table 3. Interfacial shear strength (IFSS) and schematic representation of possible interfacial interactions for different fiber surface treatments with and without MWCNTs

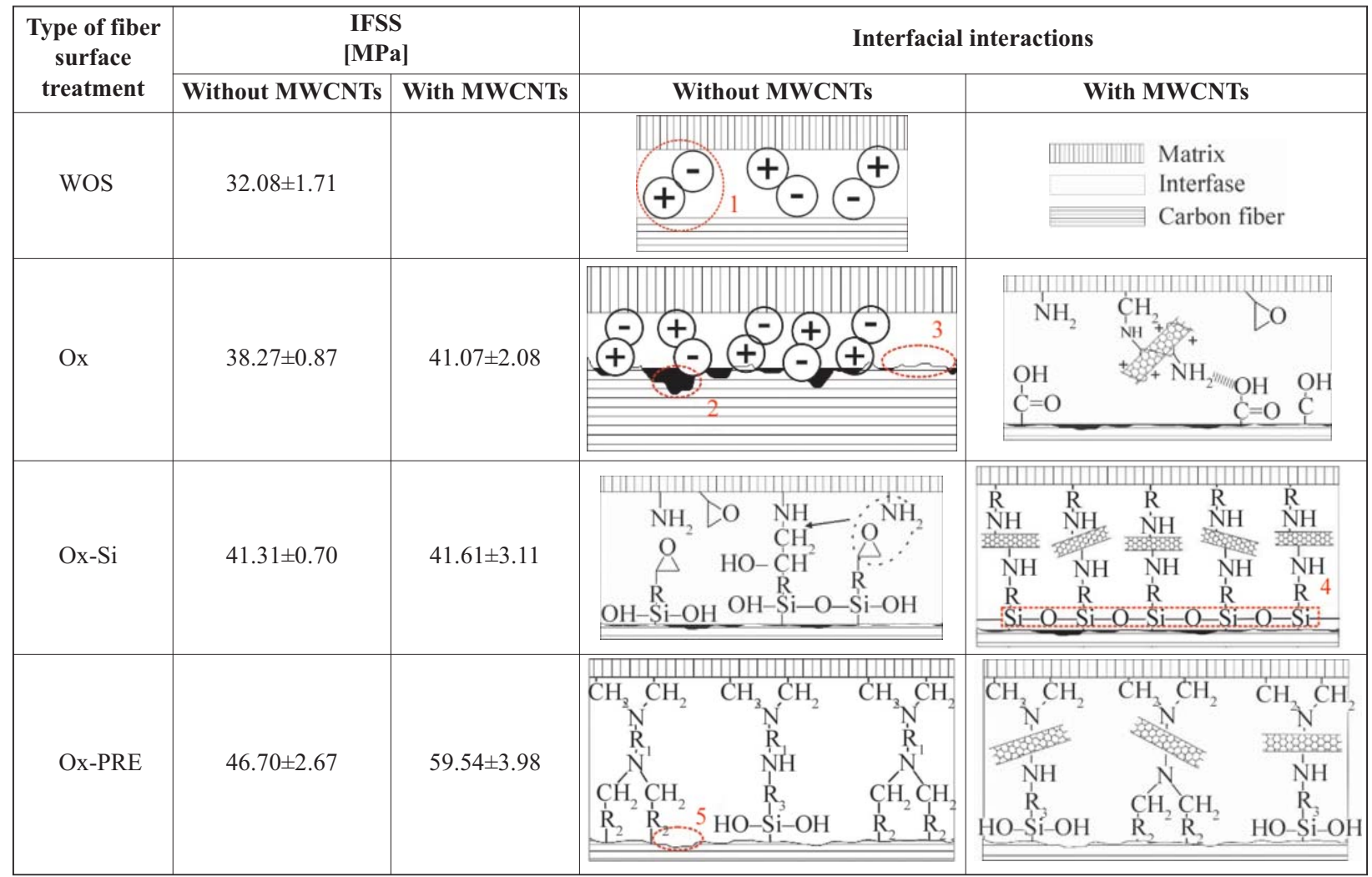

1. Acid-base interactions, 2. Voids, 3. Mechanical interactions, 4. Polysiloxanes, 5. Without voids.

and the epoxy resin (hydroxyl and oxirane). In the case WOS fiber there are only a few acid base interactions points, whereas the formation of acid-base interactions between the Ox-fibers and the matrix is enhanced. The increase in fiber-matrix compatibility, due to the increase in the polarity of the Ox fiber (with respect to the fiber WOS) is also observed with a decrease of the contact angle [4].

The system with Ox-Si fiber has an IFSS value slightly higher than that determined for the system 
with the Ox fiber. This small increase is attributed to the possible formation of covalent bonds between the epoxy group at the end of the chemical structure of the silane and the primary amines present in the crosslinking agent. The system with the Ox-PRE fiber, showed a significantly higher value of IFSS than those observed for the Ox and Ox-Si fibers. This increment of IFSS is attributed to the formation of covalent bonds between the epoxy groups present in the epoxy coating and the grafted silane of the OxPRE fiber and the amines of the crosslinking agent [23]. In addition, the pre-impregnation treatment promotes a higher degree of wettability, corroborated by a decrease of the contact angle, and infiltration of the epoxy resin on the irregular surface of the carbon fiber, allowing the resin to fill the cavities present on the surface of the fiber [28]. For systems with fibers without pre-impregnation, the viscosity of the (undiluted) epoxy resin makes it difficult to infiltrate the surface cavities of the fiber, giving rise to voids that limit the area of surface contact and consequently the transfer of interfacial shear stresses.

The IFSS values showed that the presence of MWCNTs at the interface of the Ox-CNT fibers systems resulted in a slight increase with respect to their reference (fiber Ox). The strengthening capacity of MWCNTs could be attributed to an increase in the elastic modulus of the interfacial zone because of the presence of MWCNTs which could restrict the mobility of the polymer structure of the epoxy resin surrounding the carbon fiber [37]. However, the strengthening capacity of MWCNTs could be limited by the weak chemical interactions (hydrogen bonds) that may be established between primary amines present on the MWCNTs surface and the hydroxyl and carboxylic acid groups on the fiber surface, limiting the transfer of stresses between the fiber and MWCNTs. The system with Ox-Si-CNT fiber did not show an improvement of the interfacial adhesion with respect to the system with Ox-Si fiber. In this case, the chemical interactions between the MWCNTs and the fiber would be limited because of the homopolymerization reaction of the silane to form polisiloxanes. Consequently, the MWCNTs would be limiting the wetting of the carbon fiber by the epoxy resin, which would reduce the (Ox-Si)- fiber/matrix interactions.

Thus, there exists a balance between the contribution of the MWCNTs in the interfacial elastic modulus and the hampering of fiber-matrix interactions. For the system with Ox-PRE-CNT fiber an increase of
$27.8 \%$ with respect to the system with Ox-PRE fiber and $85.6 \%$ compared to the system with WOS fiber was observed. This increase could be attributed to two factors: a) good interaction between the MWCNTs and the carbon fiber coated with epoxy resin, promoted by the pre-impregnation treatment, allowing a good diffusion of the resin among the MWCNTs dispersed in the interface, between the MWCNTs and the fiber, and the superficial cavities of the carbon fiber, and b) formation of covalent bonds between the primary amines present in the MWCNTs and in the crosslinking agent, with the epoxy groups of the fiber coating and the epoxy resin matrix. These two factors create the necessary conditions for the formation of a nanocomposite within the interphase with a modulus of elasticity higher than that of the matrix epoxy resin. It is well known that an increase in the elastic modulus the interfacial zone promotes a better stress transfer between the fiber and the matrix, due to the fact that the matrix in its interfacial zone presents less creep or yielding, transmitting a greater amount of stresses towards the fiber. Furthermore, a higher elastic modulus interface could address cracks towards the matrix, preventing its propagation through the fiber-matrix interface $[7,27,28$, 38-42].

Figure 7 shows photoelastic patterns for the different fiber-matrix systems evaluated. The light areas are zones of optical anisotropy induced in the matrix surrounding the fiber, because of the stress transfer between fiber and matrix. It should also be noted that in some cases, the optical activity extends away from the fiber, indicated by the colors in the images. It can be observed around the fiber, except in the vicinity of the fiber rupture, indicating interfacial debonding, that is, the dark region is the area where no fiber-matrix stress transfer is taking place because of the interfacial damage. For the WOS fiber, a white zone of intense luminosity is observed and also the dark area close to the zone of fiber failure. The extent of this damage zone in the vicinity of fiber rupture decreases with the surface treatments $\mathrm{Ox}>\mathrm{Ox}-\mathrm{Si}>\mathrm{Ox}$-PRE. It is also notorious that the optical activity is more intense in the order Ox-Pre $>\mathrm{Ox}-\mathrm{Si}>\mathrm{Ox}>$ WOS. To better understand the photoelastic patterns, Figure 8 shows a schematic representation of the interfacial damage evidenced for each of the different fiber-matrix systems, A decrease in the propagation of the interfacial crack for the Ox-PRE systems (Figure 8c) with respect to the systems Ox and Ox-Si (Figure 8b) 


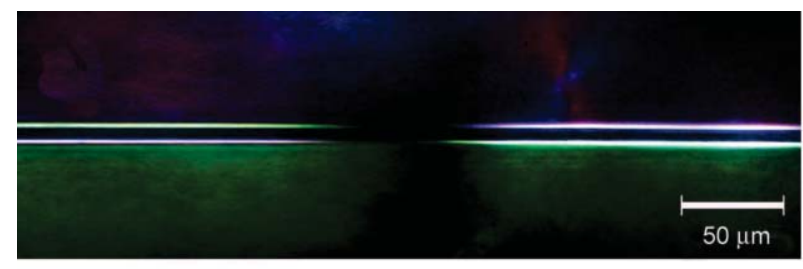

a)

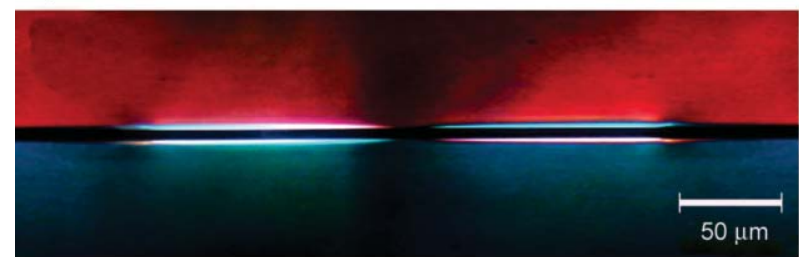

b)

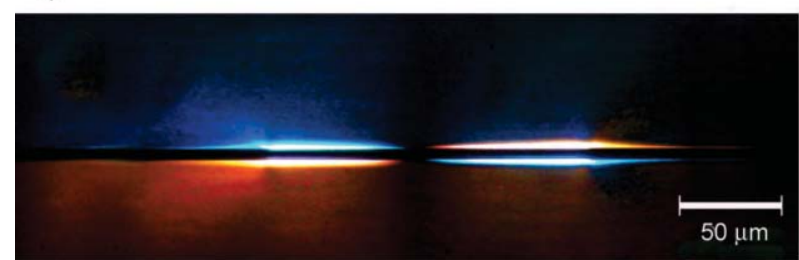

c)

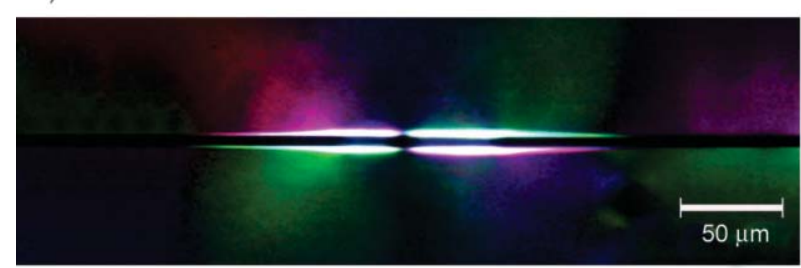

d)

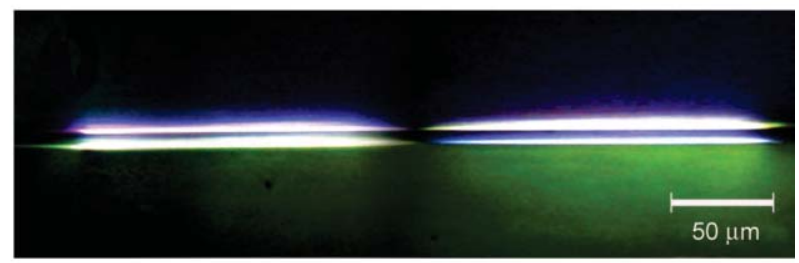

e)

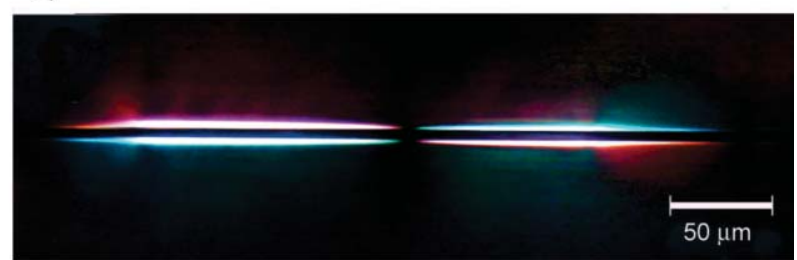

f)

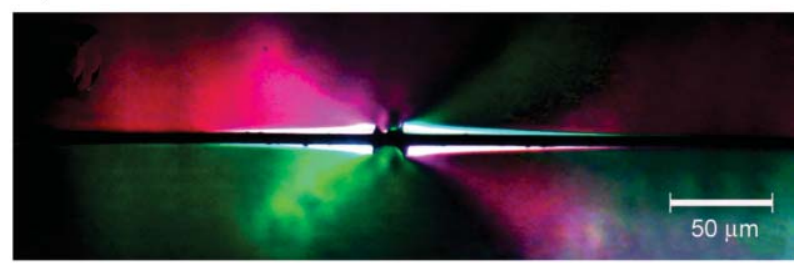

g)

Figure 7. Photoelastic patterns of stress obtained after the fragmentation of the fibers for the different fiber surface treatments: a) WOS, b) Ox, c) Ox-Si, d) Ox-PRE, e) Ox-CNT, f) Ox-Si-CNT and g) Ox-PRE-CNT

is observed. The fiber-matrix stress transfer is for the Ox-PRE fiber has a more intense and extended transfer zone towards the matrix than the systems with $\mathrm{Ox}$ and Ox-Si fibers. It can be noticed that because of the presence of MWCNTs in the interface (in all cases), the birefringence zone was more intense and it extended way from the fiber-matrix interface; this effect becomes more important and noticeable in the systems with Ox-PRE-CNT fibers (Figure 7g). Therefore, it can be said that the presence of MWNTCs modifies the elastic modulus of the matrix in the zone near the interface promoting better stress trans-

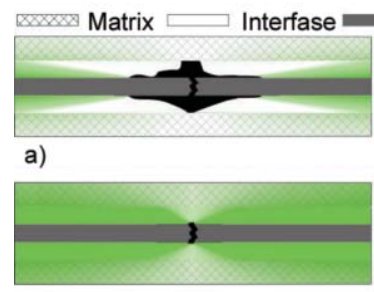

c)

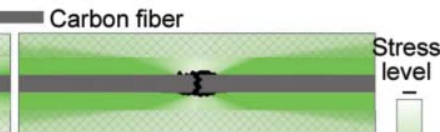

b)

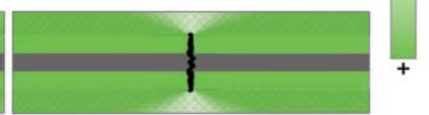

d)
Figura 8. Schematic representation of photoelastic stress patterns for fiber-matrix systems with: a) WOS, b) Ox and $\mathrm{Ox}-\mathrm{Si}$, c) Ox-PRE, Ox-CNT and Ox-SiCNT and d) Ox-PRE-CNT fer between the composite phases. Furthermore, for the systems of high adhesion level (Ox-PRE-CNT) a small dark zone in the vicinity of the fiber fracture is noticed to extend towards the matrix and is surrounded by a region of high-intensity optical activity. In this case, the matrix crack will either grow or result in matrix yielding (failure mechanism shown in Figure 8d). Similar observations were made by Kamae et al. [23] who observed that the fiber fragmentation occurred at lower strain values for the incorporation of the MWCNTs and the preimpregnation with an epoxy sizing resulted in a higher IFSS and attributed such increase to a higher elastic modulus and strength of the interface.

To corroborate the hypotheses outlined above, a microdrop of epoxy resin deposited and cured on the WOS, Ox-PRE and Ox-PRE-CNT fibers. The type of failure was observed by scanning electron microscopy (SEM). In Figure 9a and it is possible to observe that the process of interfacial debonding for the WOS fiber did not generate failure in the microdrop nor there is any resin residues on the surface of the fiber, typical characteristics of a poor Interfacial 
adhesion debonding. For the Ox-PRE fibers (Figure $9 \mathrm{~b}$ ) small resin residues are seen on the fiber surface and failure at the end of the microdrop after debonding, suggesting a stronger fiber-matrix adhesion. For the Ox-PRE-CNT fibers it can be observed that the fiber was completely covered with epoxy resin residues, indicating that a coating with an elastic modulus higher than the matrix elastic modulus

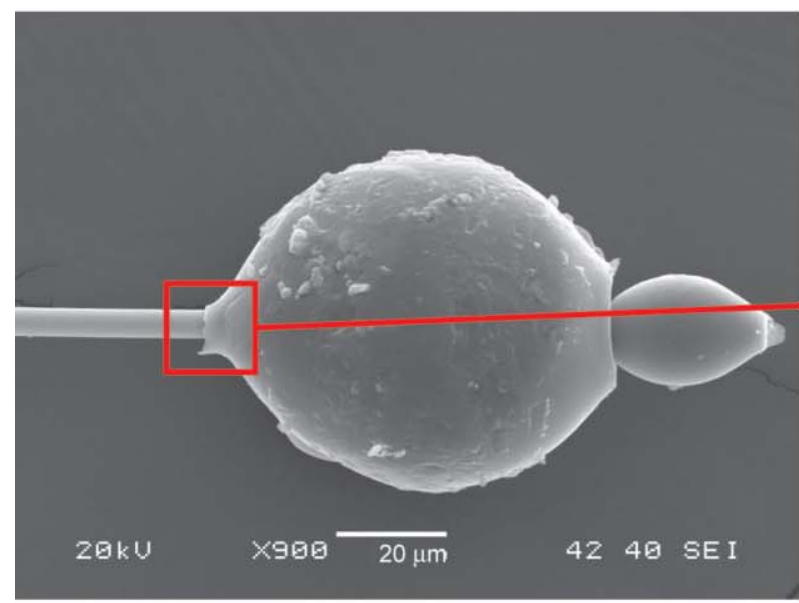

a)

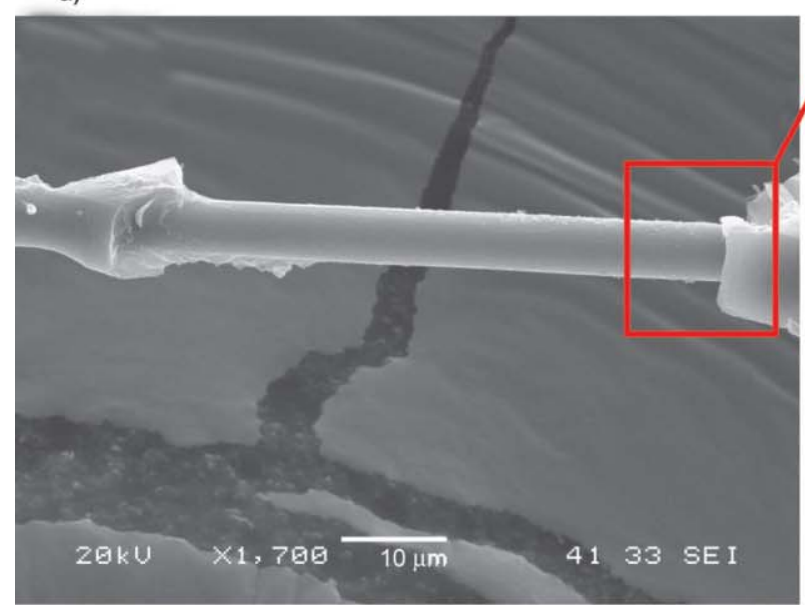

b)
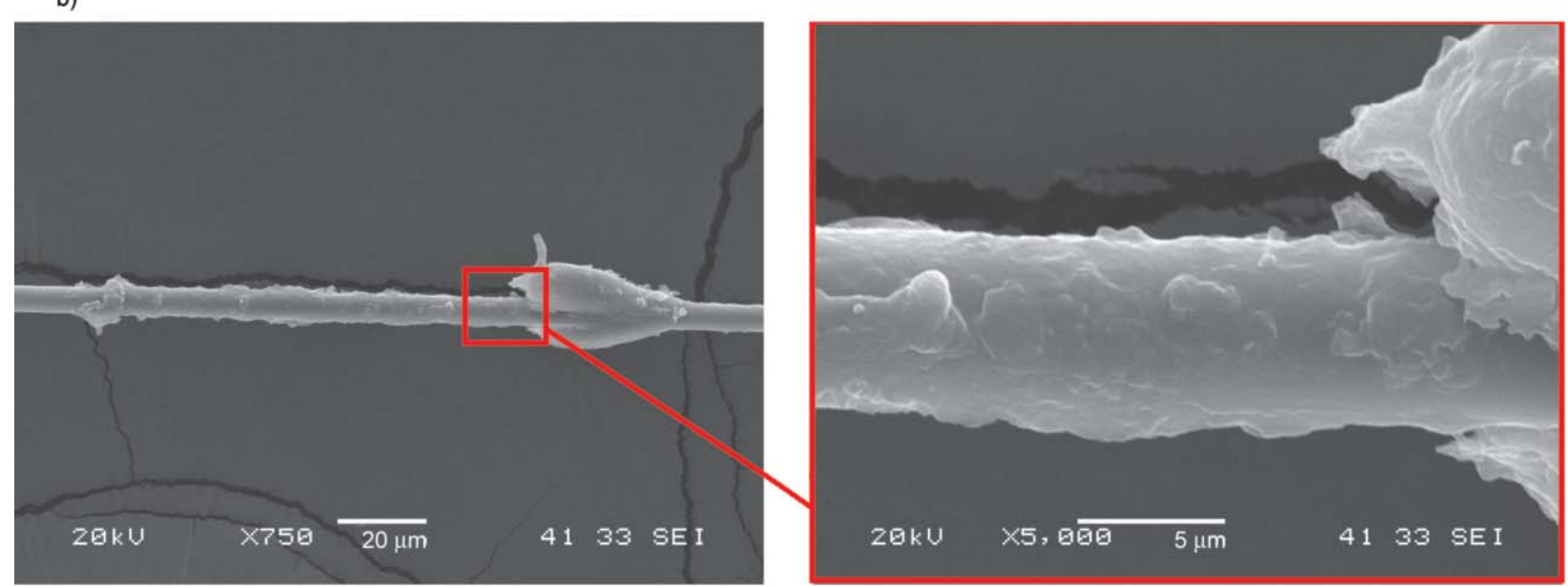

c)

Figure 9. SEM micrographs of fiber-matrix interfacial debonding zone, after extraction of a microdrop deposited on a) WOS fiber, b) Ox-PRE fiber and c) Ox-PRE-CNT fibers

was generated on the fiber and that the interfacial failure propagated on this coating, which was previously referred to as a 'MWCNTs/resin nano-composite'. Then, the carbon fiber coated by the nanocomposite results in a fiber of larger diameter than that of the carbon fiber without any treatment, suggesting that the IFSS in the Ox-PRE-CNT systems could be slightly higher than that determined and
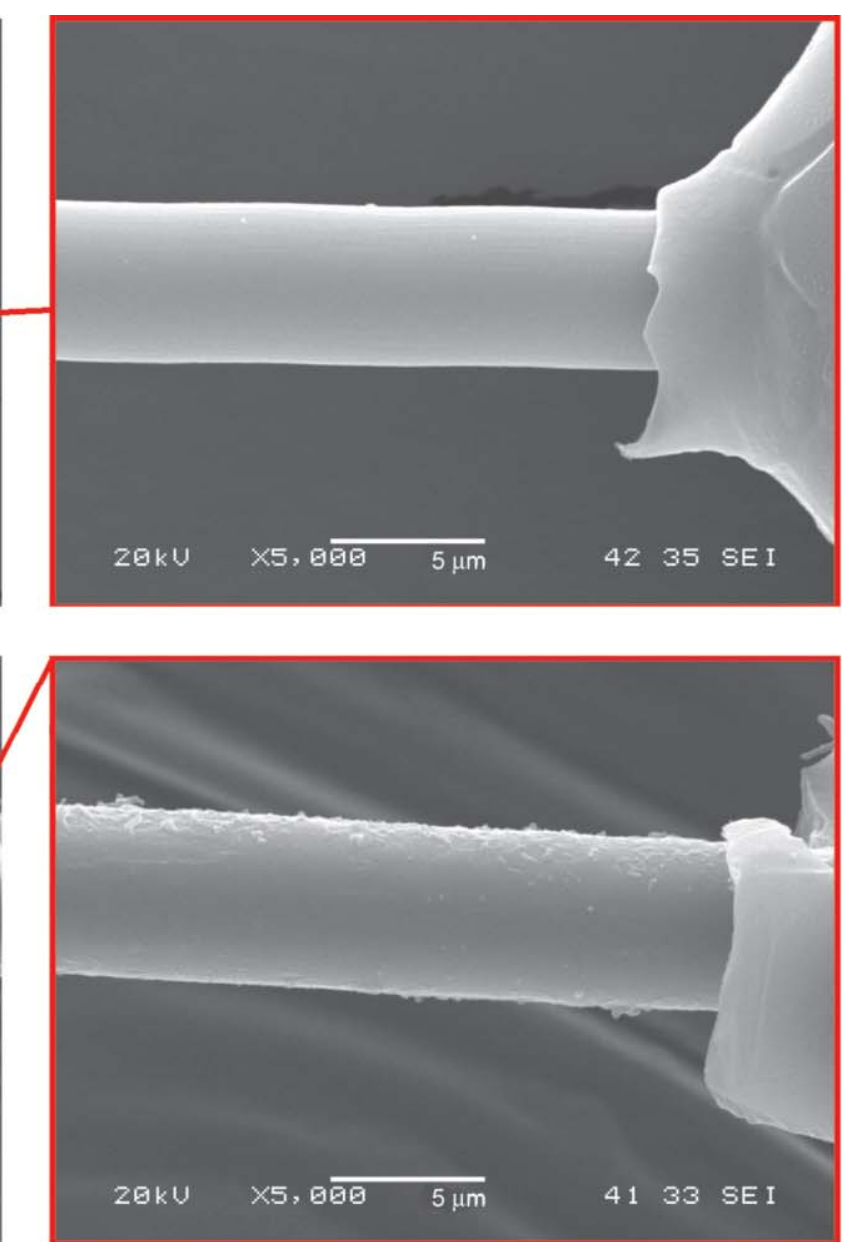
fiber, b) Ox-PRE fiber and c) Ox-PRE-CNT fibers 
presented in Table 3, which was calculated using the diameter of the fiber prior to coating. It was also evident that the interfacial failure extended into the microdrop, causing a catastrophic debonding (Figure 9c), an event that occurs when the interface has a greater modulus of elasticity than that of the matrix [7].

\section{Conclusions}

The contact angle results showed that with the OxPRE surface treatment of the carbon fiber it is possible to increase the wetting of the fiber by $51.93 \%$ with respect to WOS fibers, due to the increase in the compatibility between materials of the same origin, epoxy coating and epoxy resin matrix.

The efficiency of MWCNTs deposited on the surface of the carbon fiber in the transfer of interfacial shear stresses is highly influenced by the type of surface treatment previously performed on carbon fiber because it could affect the distribution and dispersion of the MWCNTs at the interface. The IFSS estimated values showed that with the Ox-PRE-CNT system there is an increase of $27.80 \%$, for the Ox-CNT system an increase of $7.31 \%$ and for the Ox-Si-CNT system there is no significant increase, each with respect to its reference.

From the results obtained from the SFFT (IFSS and photoelastic patterns) and the failure mode observation in SEM micrographs in the zone of interfacial debonding of the deposited microdrops and debonded off the fibers, it can be concluded that the incorporation of MWCNTs at the interface increases the elastic modulus of the interfacial zone allowing a better transfer of stresses between the fiber and the matrix. In addition, from the fracture mode in the system with Ox-PRE-CNT fibers it can be said that the propagation of failure for this fiber-matrix system propagates to the interior of the matrix and its propagation on the interfacial zone is limited, because its elastic modulus exceeds that of the matrix.

\section{Acknowledgements}

The authors wish to express their gratitude for the financial support from CONACYT (Grant CB-2012-01, Clave 183418). The help of Miss Silvia Andrade-Canto with the SEM pictures and the help given for the fiber surface chemical treatments by Mrs. M. Veronica Moreno Chulim and Hugo J. Carrillo-Escalante, and help from Javier I. Cauich-Cupul with the single-fiber fragmentation tests are greatly appreciated.

\section{References}

[1] Pérez-Pacheco E., Moreno-Chulim M. V., ValadezGonzález A., Rios-Soberanis C. R., Herrera-Franco P. J.: Effect of the interphase microstructure on the behavior of carbon fiber/epoxy resin model composite in a thermal environment. Journal of Materials Science, 46, 4026-4033 (2011). https://doi.org/10.1007/s10853-011-5331-0

[2] Ma L., Meng L., Wu G., Wang Y., Zhao M., Zhang C., Huang Y.: Effects of bonding types of carbon fibers with branched polyethyleneimine on the interfacial microstructure and mechanical properties of carbon fiber/ epoxy resin composites. Composites Science and Technology, 117, 289-297 (2015).

https://doi.org/10.1016/j.compscitech.2015.06.018

[3] Wu G., Ma L., Liu L., Wang Y., Xie F., Zhong Z., Zhao M., Jiang B., Huang Y.: Interfacially reinforced methylphenylsilicone resin composites by chemically grafting multiwall carbon nanotubes onto carbon fibers. Composites Part B: Engineering, 82, 50-58 (2015). https://doi.org/10.1016/j.compositesb.2015.08.012

[4] Drzal L.T., Rich M. J., Lloyd P. F.: Adhesion of graphite fibers to epoxy matrices: I. The role of fiber surface treatment. The Journal of Adhesion, 16, 1-30 (1983). https://doi.org/10.1080/00218468308074901

[5] Kim M. T., Rhee K. Y., Lee J. H., Hui D., Lau A. K. T.: Property enhancement of a carbon fiber/epoxy composite by using carbon nanotubes. Composites Part B: Engineering, 42, 1257-1261 (2011).

https://doi.org/10.1016/j.compositesb.2011.02.005

[6] Afaghi-Khatibi A., Ye L., Mai Y-W.: An experimental study of the influence of fibre-matrix interface on fatigue tensile strength of notched composite laminates. Composites Part B: Engineering, 32, 371-377 (2001). https://doi.org/10.1016/S1359-8368(01)00012-9

[7] Sager R. J., Klein P. J., Lagoudas D. C., Zhang Q., Liu J., Dai L., Baur J. W.: Effect of carbon nanotubes on the interfacial shear strength of T650 carbon fiber in an epoxy matrix. Composites Science and Technology, 69, 898-904 (2009).

https://doi.org/10.1016/j.compscitech.2008.12.021

[8] Thostenson E. T., Li W. Z., Wang D. Z., Ren Z. F., Chou T. W.: Carbon nanotube/carbon fiber hybrid multiscale composites. Journal of Applied Physics, 91, 6034-6037 (2002).

https://doi.org/10.1063/1.1466880

[9] Zhao F., Huang Y., Liu L., Bai Y., Xu L.: Formation of a carbon fiber/polyhedral oligomeric silsesquioxane/ carbon nanotube hybrid reinforcement and its effect on the interfacial properties of carbon fiber/epoxy composites. Carbon, 49, 2624-2632 (2011). https://doi.org/10.1016/j.carbon.2011.02.026

[10] Mei L., Li Y., Wang R., Wang C., Peng Q., He X.: Multiscale carbon nanotube-carbon fiber reinforcement for advanced epoxy composites with high interfacial strength. Polymers and Polymer Composites, 19, 107-112 (2011). 
[11] Cauich-Cupul J. I., Pérez-Pacheco E., Valadez-González A., Herrera-Franco P. J.: Effect of moisture absorption on the micromechanical behavior of carbon fiber/ epoxy matrix composites. Journal of Materials Science, 46, 6664-6672 (2011). https://doi.org/10.1007/s10853-011-5619-0

[12] Sharma M., Gao S., Mäder E., Sharma H., Wei L. Y., Bijwe J.: Carbon fiber surfaces and composite interphases. Composites Science and Technology, 102, 3550 (2014).

https://doi.org/10.1016/j.compscitech.2014.07.005

[13] Karger-Kocsis J., Mahmood H., Pegoretti A.: Recent advances in fiber/matrix interphase engineering for polymer composites. Progress in Materials Science, 73, 1-43 (2015).

https://doi.org/10.1016/j.pmatsci.2015.02.003

[14] Ben S., Zhao J., Zhang Y., Qin Y., Rabczuk T.: The interface strength and debonding for composite structures: Review and recent developments. Composite Structures, 129, 8-26 (2015).

https://doi.org/10.1016/j.compstruct.2015.03.036

[15] Pandey G., Wolters M., Thostenson E. T., Heider D.: Localized functionally modified glass fibers with carbon nanotube networks for crack sensing in composites using time domain reflectometry. Carbon, 50, 38163825 (2012).

https://doi.org/10.1016/j.carbon.2012.04.008

[16] Uribe B. E. B., Chiromito E. M. S., Carvalho A. J. F., Tarpani J. R.: Low-cost, environmentally friendly route for producing CFRP laminates with microfibrillated cellulose interphase. Express Polymer Letters, 11, 47 59 (2017).

https://doi.org/10.3144/expresspolymlett.2017.6

[17] Pegoretti A., Karger-Kocsis J.: Interphase engineering in polymer composites: Challenging the devil.... Express PolymerLetters, 9, 838 (2015).

https://doi.org/10.3144/expresspolymlett.2015.78

[18] Ci L., Suhr J., Pushparaj V., Zhang X., Ajayan P. M.: Continuous carbon nanotube reinforced composites. Nano Letters, 8, 2762-2766 (2008).

https://doi.org/10.1021/nl8012715

[19] Dong B., Yang Z., Huang Y., Li H-L.: Study on tribological properties of multi-walled carbon nanotubes/ epoxy resin nanocomposites. Tribology Letters, 20, 251-254 (2005).

https://doi.org/10.1007/s11249-005-8637-8

[20] Fiedler B., Gojny F. H., Wichmann M. H. G., Nolte M. C. M., Schulte K.: Fundamental aspects of nano-reinforced composites. Composites Science and Technology, 66, 3115-3125 (2006).

https://doi.org/10.1016/j.compscitech.2005.01.014

[21] Lachman N., Carey B. J., Hashim D. P., Ajayan P. M., Wagner H. D.: Application of continuously-monitored single fiber fragmentation tests to carbon nanotube/carbon microfiber hybrid composites. Composites Science and Technology, 72, 1711-1717 (2012).

https://doi.org/10.1016/j.compscitech.2012.06.004
[22] Lachman N., Wiesel E., Guzman de Villoria R., Wardle B. L., Wagner H. D.: Interfacial load transfer in carbon nanotube/ceramic microfiber hybrid polymer composites. Composites Science and Technology, 72, 14161422 (2012).

https://doi.org/10.1016/j.compscitech.2012.05.015

[23] Kamae T., Drzal L. T.: Carbon fiber/epoxy composite property enhancement through incorporation of carbon nanotubes at the fiber-matrix interphase - Part I: The development of carbon nanotube coated carbon fibers and the evaluation of their adhesion. Composites Part A: Applied Science and Manufacturing, 43, 1569-1577 (2012).

https://doi.org/10.1016/j.compositesa.2012.02.016

[24] Bekyarova E., Thostenson E. T., Yu A., Kim H., Gao J., Tang J., Hahn H. T., Chou T-W., Itkis M. E., Haddon R. C.: Multiscale carbon nanotube-carbon fiber reinforcement for advanced epoxy composites. Langmuir, 23, 3970-3974 (2007). https://doi.org/10.1021/la062743p

[25] Vautard F., Ozcan S., Paulauskas F., Spruiell J. E., Meyer H., Lance M. J.: Influence of the carbon fiber surface microstructure on the surface chemistry generated by a thermo-chemical surface treatment. Applied Surface Science, 261, 473-480 (2012).

https://doi.org/10.1016/j.apsusc.2012.08.038

[26] Yamaki J-I., Katayama Y.: New method of determining contact angle between monofilament and liquid. Journal of Applied Polymer Science, 19, 2897-2909 (1975). https://doi.org/10.1002/app.1975.070191025

[27] Herrera-Franco P. J., Drzal L. T.: Comparison of methods for the measurement of fibre/matrix adhesion in composites. Composites, 23, 2-27 (1992). https://doi.org/10.1016/0010-4361(92)90282-Y

[28] Drzal L. T., Rich M. J., Koening M. J., Lloyd P.: Adhesion of graphite fibers to epoxy matrices: II. The effect of fiber finish. The Journal of Adhesion, 16, 133-152 (1983). https://doi.org/10.1080/00218468308074911

[29] Ganguli S., Roy A. K., Anderson D. P.: Improved thermal conductivity for chemically functionalized exfoliated graphite/epoxy composites. Carbon, 46, 806-817 (2008). https://doi.org/10.1016/j.carbon.2008.02.008

[30] Chen C., Liang B., Ogino A., Wang X., Nagatsu M.: Oxygen functionalization of multiwall carbon nanotubes by microwave-excited surface-wave plasma treatment. The Journal of Physical Chemistry C, 113, 76597665 (2009). https://doi.org/10.1021/jp9012015

[31] Tzounis L., Kirsten M., Simon F., Mäder E., Stamm M.: The interphase microstructure and electrical properties of glass fibers covalently and non-covalently bonded with multiwall carbon nanotubes. Carbon, 73, 310-324 (2014). https://doi.org/10.1016/j.carbon.2014.02.069 
[32] Vanzetti L., Pasquardini L., Potrich C., Vaghi V., Battista E., Causa F., Pederzolli C.: XPS analysis of genomic DNA adsorbed on PEI-modified surfaces. Surface and Interface Analysis, 48, 611-615 (2016).

https://doi.org/10.1002/sia.5932

[33] Langston T. A.: Wettability of nitric acid oxidized carbon fibers. Journal of Reinforced Plastics and Composites, 29, 2156-2169 (2009). https://doi.org/10.1177/0731684409341756

[34] Luo Y., Zhao Y., Duan Y., Du S.: Surface and wettability property analysis of CCF300 carbon fibers with different sizing or without sizing. Materials and Design, 32, 941-946 (2011).

https://doi.org/10.1016/j.matdes.2010.08.004

[35] Jiang G., Pickering S. J.: Structure-property relationship of recycled carbon fibres revealed by pyrolysis recycling process. Journal of Materials Science, 51, 1949-1958 (2016).

https://doi.org/10.1007/s10853-015-9502-2

[36] Fitzer E., Geigl K-H., Hüttner W., Weiss R.: Chemical interactions between the carbon fibre surface and epoxy resins. Carbon, 18, 389-393 (1980).

https://doi.org/10.1016/0008-6223(80)90029-9

[37] Hernández-Ramírez L.: Análisis paramétrico del estado de esfuerzos en un modelo de un material compuesto multi-escala monofilamento de carbono/nanotubos de carbono-resina epóxica. Master's degree thesis. Centro de Investigación Científica de Yucatán, Mérida, México (2014).
[38] Gojny F. H., Wichmann M. H. G., Köpke U., Fiedler B., Schulte K.: Carbon nanotube-reinforced epoxycomposites: Enhanced stiffness and fracture toughness at low nanotube content. Composites Science and Technology, 64, 2363-2371 (2004).

https://doi.org/10.1016/j.compscitech.2004.04.002

[39] Gojny F. H., Wichmann M. H. G., Fiedler B., Schulte $\mathrm{K}$.: Influence of different carbon nanotubes on the mechanical properties of epoxy matrix composites - A comparative study. Composites Science and Technology, 65, 2300-2313 (2005).

https://doi.org/10.1016/j.compscitech.2005.04.021

[40] Yeh M-K., Hsieh T-H., Tai N-H.: Fabrication and mechanical properties of multi-walled carbon nanotubes/ epoxy nanocomposites. Materials Science and Engineering: A, 15, 289-292 (2008).

https://doi.org/10.1016/j.msea.2006.09.138

[41] Hernández-Pérez A., Avilés F., May-Pat A., ValadezGonzález A., Herrera-Franco P. J., Bartolo-Pérez P.: Effective properties of multiwalled carbon nanotube/epoxy composites using two different tubes. Composites Science and Technology, 68, 1422-1431 (2008). https://doi.org/10.1016/j.compscitech.2007.11.001

[42] Drzal L. T.: The effect of polymeric matrix mechanical properties on the fiber-matrix interfacial shear strength. Materials Science and Engineering: A, 126, 289-293 (1990). https://doi.org/10.1016/0921-5093(90)90135-P 